\title{
German Idealism and early German Romanticism
}

\section{Thinking the infinite}

The immediate consequences from the 1790s onwards of the perceived failure of Kant's attempt to ground philosophy in the principle of subjectivity are apparent in two areas of philosophy which carry the broad names 'German Idealism', which is mainly associated with Fichte, Schelling and Hegel; and 'early Romanticism', which is mainly associated with Novalis, Friedrich Schlegel and (in some respects) Friedrich Schleiermacher. ${ }^{1}$ There are, as we shall see, crucial respects in which these two currents of thought can be distinguished. It would, though, be mistaken to regard either German Idealism or early Romanticism as unified philosophical schools, which is one reason why they have often, albeit mistakenly, been assimilated to each other. The problem is that, despite their differences, aspects of each are often found in the other: Schelling, for instance, can be seen as at times belonging both to Idealism and to Romanticism. A further complicating factor here is that 'early Romanticism' must be specified in this way to distinguish it from later reactionary doctrines which bear the name Romanticism in Germany. The term Romanticism is notoriously vague, and it is important to see that the early Romantics, who, after all, themselves established the term, can be characterised in a way which distinguishes them from later German Romanticism. What is at stake in this distinction is easily illustrated by the fact that the Nazis were not in the least bit fond of the early Romantics, who had a thoroughly cosmopolitan orientation and were therefore resistant to the nationalist assimilation of 'Romanticism' into Nazi ideology.

Peter Szondi maintains of German Idealism that 'One could say crudely that the philosophy of German Idealism tried to win back via the path of speculation what Kant's criticism had to renounce: the unity of subject and object, of mind and nature' (Szondi 1974 p. 221). 'German Idealism', which I shall generally refer to as 'Idealism' from now on, has little to do with the philosophical idealism represented by Berkeley's claim that 'being is perceiving'. Kant already objected to such idealism when he insisted upon the need in 'transcendental idealism' for intuitions given from outside the subject to fill the concepts of the understanding, if anything is to be considered as real - though his arguments 
were anything but decisive, as Salomon Maimon and others showed at the time (see Frank 1997). In the present context, however, the basic idea of transcendental idealism can be understood as follows: although objectivity depends upon a subject which constitutes an object as an object of truth in a judgement, the subject does not create the material which is judged to be the object at issue. The central question in Idealism is really, then, how what the subject does relates to the nature of which it is a part. This leads to questions both about the very fact that there is subjectivity at all, rather than there just being a world which does not come to know itself, and about the status of the forms of thinking in relation to forms in the rest of nature.

In the wake of Kant the philosophical unification of subject and object is seen as entailing the subject's explication of the identity between itself as autonomous, 'intelligible' subject, and itself as knowable object of intuition in the world of deterministic appearing nature. In other words, an explanation is required both of the relationship between the spontaneity of the subject and the materially instantiated activity of the rest of nature, including our own brains and the rest of our bodies, and of how we can know about this relationship. In 1784 Jacobi already asks how we can claim, as Kant does, that nature 'in itself' gives rise to appearances in the subject at all, if, as Kant also insists, nature in itself is topically separate from what we can know about it. Responses to these issues - which Kant began to develop in the $C F$ - need to offer ways of showing that the realms of necessity and freedom cannot ultimately be separate because the purposes which guide my free moral action are connected to the overall purpose of nature manifested in myself as natural being. One way in which the Idealists try to conceive of such a unification is in terms of each passing, sensuous, 'conditioned' moment of experience finding its truth in the totality, the 'unconditioned' or the 'absolute', which gives it its meaning, as opposed to its being simply another part of an endless, arbitrary sequence of what Jacobi termed 'conditioned conditions' (see Bowie 1997 Chapter 1). Jacobi's own arguments aim at revealing the inability of Enlightenment philosophy (which for him includes Kant) to ground the fact that the world is intelligible at all. He thinks such a philosophical grounding inherently impossible, which means he responds to the fact of the world's intelligibility by belief in a grounding deity. For the Idealists, who are, initially at least, opposed to established theology, the impetus behind the idea of the unconditioned is the replacement of theology in the name of human self-determination. Jacobi's arguments concerning the regress of conditioned conditions and the limits of rationalism are therefore regarded as likely to revive such theology. In consequence Idealist philosophy seeks an alternative account of our relationship to the unconditioned which does not have to rely upon something that transcends human reason. Idealism can, then, be seen as reflecting upon what it would mean for knowing and the value of knowing no longer to be separate, without the connection between the two involving reference to a deity. The fact that this reflection will lead in both philosophical and theological directions will be crucial to Idealism's relationship to aesthetics. 
A vital problem here is that if the finite, conditioned moments of existence are to become part of a unified, unconditioned totality they must in some way be 'negated', because they can never be sufficient in themselves. Such negation can, however, easily be construed as the mere abolition of the finite by the infinite, which renders the finite meaningless. This was why Jacobi thought modern science led inexorably to what he came to term 'nihilism', in which each explained condition is just the condition of another condition, and so on, in an infinite regress. In consequence, a philosophical account of the relationship between the finite and the infinite which comes to terms with the possibility of nihilism is a central aim of Idealism. One response of Idealist philosophy to Kant's dualism is, as a result of the controversy occasioned from 1783 onwards by Jacobi over whether Spinozism is necessarily a kind of atheism (see Bowie 1997 Chapter 1), a concern with Spinoza's monism, which obviates any final separation of subject and object.

Much of Idealist thought relies in varying ways on Spinoza's dictum that 'all determination is negation': something can only be what it is by its not being everything else, which defines what it is not. The subject's ability to move beyond anything specific, in order to establish the particular thing's identity in terms of its relations to other particulars and ultimately to the totality, is seen as demonstrating that mithin subjectivity there is a capacity which is unlimited, 'infinite', in a much more emphatic sense than Kant's account of reason would allow. Idealist philosophy tries to articulate what this ability to move beyond limitation means for philosophy, seeking ways of rethinking the relationship between the finite and the infinite without regressing into the dogmatic metaphysics which Kant had refuted. One of these ways is via the experience of the work of art, which is regarded, in the manner of the $C \mathcal{F}$, as an object whose individual parts are transcended into a greater whole, and which is therefore understood as offering a kind of insight which is inaccessible to philosophy. One of the other ways will be Hegel's attempt to create a system of thought which reconciles us to nihilism via philosophical insight into the inherent necessity of the abolition of every finite particular. The relationship between these two contrasting approaches, one of which suggests the limits of philosophy's ability to articulate the highest truths, the other of which regards art as merely a stage on the way to the real truth revealed by philosophy, is the basis of much of what this book has to say. Do art and philosophy have the same purpose, or can they be separated? What does this mean for philosophy and for art in modernity? The contrasts between the Romantics, Schelling and Hegel will have paradigmatic significance for these issues.

The essential thought behind the Romantic, as opposed to the Idealist, view of the post-Kantian situation was already present in the implications of Kant's notion of the sublime. The sublime resulted from the inability of thought to represent the infinite in the sensuous. At the same time the experience of the sublime aroused a sense of the infinite in the subject via the feeling of finitude it produced. In line with Kant, and in contrast to Idealism, early Romanticism 
acknowledges the ultimate philosophical inaccessibility of the absolute but, somewhat in the manner of Kant's Schwärmer, will not give up the endless attempt to grasp the infinite via the sensuous. The consequence of this endless failure is manifest in 'longing', a notion that plays a major role in both Romantic philosophy and art. Longing results from our inherent dissatisfaction with any claim to have attained the final truth via something in the transient empirical world. Friedrich Schlegel says of the sublime: 'The feeling of the sublime must naturally arise for everyone who has really abstracted. Whoever has really thought the infinite can never again think the finite' (Schlegel 19885 p. 98). The absolute therefore becomes unrepresentable: 'The impossibility of positively reaching the Highest by reflection leads to allegory' (p. 105), because allegory is the form in which what is represented is not what is meant. The result of the activity of the understanding can only be the dissection of reality; that which could reassemble it is only accessible via the sense of loss present in longing: 'The essence of philosophy consists in the longing for the infinite and the training of the understanding' (p. 99). It is important to note here, against a common image of Romanticism, that (as elsewhere) Schlegel clearly does not advocate a rejection of the results of modern science produced by the understanding, in favour of some kind of mystical longing, but rather seeks an integration of science into a more all-encompassing conception of reality. However, Schlegel's conception does not lead to Hegel's attempt to integrate all aspects of modern existence into a philosophical system which would show how the real has the same structure as thought. The question is whether the philosophical attempt to represent that which is unrepresentable is not mere selfdelusion.

As I shall show later, the Romantics' arguments have distinct echoes in aspects of post-structuralism: a philosophy of inherent incompleteness can be construed as a philosophy of deferral. It should be remembered, however - and this is what separates Romanticism from deconstruction - that if there were not some, perhaps inarticulable, sense of a lacking completion, the notion of deferral would be meaningless. Deferral means putting off for later, not abolishing. At the same time, the question remains - and it is still alive in contemporary philosophy, in the difference, for example, between Hilary Putnam and Richard Rorty - whether the Romantic regulative idea of truth as the goal of our spiritual life might not better be abandoned. Rorty argues, for example, that 'there is nothing that can plausibly be described as a goal of inquiry, although the desire for further justification, of course, serves as a motive of inquiry' (Rorty $1998 \mathrm{p}$. 38). In consequence 'truth' as a regulative idea is 'an ever-retreating goal, one that fades forever and forever when we move. It is not what common sense would call a goal. For it is neither something we might realise we had reached, nor something to which we might get closer' (p. 39). Putnam, in contrast, insists, like the Romantics, that: 'The very fact that we speak of our different conceptions as different conceptions of rationality posits a Grenzbegriff, a limit-concept of the ideal truth' (Putnam 1981 p. 216). 
Much depends here upon how the notion of truth is conceived. The significance of Romantic aesthetic thinking lies not least in its incorporation of a normative sense of the need to attend to all our relations to the world in terms of truth, rather than merely to our cognitive relation to the world of objects investigated by science. Manfred Frank's recent work (for example, 1997) has tended to interpret the Romantics rather too much in terms of their links to contemporary 'metaphysical realism', thereby restricting the interpretative perspective to epistemology. The Romantic notion of the absolute cannot, though, be straightforwardly assimilated to the metaphysical realist idea that the world independent of our finite, fallible knowledge of it is the true world, but involves instead an awareness that knowing things, as Stanley Cavell has suggested, is not the only way of relating to them. Even if we could know that our knowledge indeed corresponded to reality (assuming one could make sense of the idea of truth as correspondence of sentences or ideas to reality anyway), this would not solve the really important philosophical problems in modernity. Schlegel suggests why in the following remark: 'In truth you would be distressed if the whole world, as you demand, were for once seriously to become completely comprehensible' (Schlegel 19882 p. 240), and he observes elsewhere that 'If absolute truth were found then the business of spirit would be completed and it would have to cease to be, since it only exists in activity' (Schlegel 1991 p. 93). The idea of knowing everything, then, can just as easily lead to nihilism as can the scepticism which anyway inevitably results from metaphysical realism - if reality is pholly independent of what we think about it, nothing could ever confirm, in thought, that what we think is true of that reality. Both the idea of omniscience and radical scepticism involve the metaphysical realist assumption as a limiting 'absolute', but both, as Schlegel realises, fail to deal with the sort of relations to the world which give it meaning. ${ }^{2}$

The history of these ideas is an area of considerable complexity, and it is becoming clear that the stories told about the implications of Idealism and Romanticism are in need of considerable revision in the light of changing conceptions in contemporary philosophy. The standard story of German Idealism is that it is inaugurated by Fichte's radicalisation of Kant's turn to the subject, is continued in Schelling's System of Transcendental Idealism (STI) and 'identity philosophy', and culminates in Hegel's system. Hegel is then superseded by Marx, who turns Hegel's speculation into a new form of materialist philosophy. A logic of development is thereby suggested which is implicitly Hegelian: each stage of the process takes up the truth of the previous stage, refutes that stage's errors, and moves on to a higher stage. Views of history based on a necessary underlying continuity are, however, highly questionable: they follow Hegel in presupposing that what emerges from such conflicts is part of an inherent developing truth. It is, though, often the case that what has apparently been superseded has in fact merely been repressed, and will return later because it was never fully articulated. The recent attention in post-structuralism and elsewhere to the kind of questioning of the notion of truth characteristic of the work 
of Heidegger clearly has its roots in the unresolved issues of post-Kantian philosophy, rather than in a continuous philosophical development.

My contention is, therefore, that it is possible to tell a different story about the relationship of Idealism and early Romanticism to subsequent philosophy, which shows that very few of their concerns have really disappeared from the agenda of that philosophy. This is already evident if one looks at the role of aesthetic theory in the philosophy of the period with contemporary eyes. That Richard Rorty should now regard philosophy as a kind of literature, because he does not think it is possible for it to establish a privileged role in relation to other ways of articulating the world, is not fortuitous. Such a notion has nothing surprising about it for a Romantic thinker, and is not alien to Schelling's STI, which sees art as able to show what philosophy cannot say. It is, though, important to remember here that the major role given to art in German Idealism and early Romanticism is not just, as it is sometimes taken to be in the secondary literature, the result of exaggerated expectations about the ability to link the sensuous and the intelligible in a positive way, such that art directly symbolises the absolute. Often art is understood rather as 'deconstructing' the boundary between the intelligible and the sensuous, thus suggesting why philosophical attempts to define their respective roles in our constitution of the world are unlikely to succeed, and pointing to the need for other kinds of orientation in a post-theological world.

The increased importance of art in this period results, then, from the realisation that if collectively warranted truth were only available in the form of natural science based on empirical observation and the establishing of causal relations, we might be living in the nihilistic world of 'conditioned conditions' feared by Jacobi. The only truth in such a world results from the subsumption of natural phenomena under general laws, a subsumption which contemporary cognitive science now seeks, of course, to extend to the explanation of the subject's own thinking. The vital objection to conceptions like those now dominating cognitive science (and the public culture it has helped to create) is Kantian: what can cause something that is supposed to be exclusively causally explicable to apprehend itself as causal in the first place? Why does it bother? The whole point of transcendental philosophy is that there is a limit to the subject's capacity for self-objectification which forces philosophy beyond the conditioned world towards the exploration of what makes it possible to apprehend conditions as conditions, or, indeed, apprehend anything as anything at all. Whatever this is would seem therefore itself to be in some sense unconditioned, and thus inaccessible to knowledge of the kind we have of objects that are 'real', in Kant's sense of 'being given in intuition' - whence Kant's difficulties with the status of the I in the transcendental deduction.

Interpreting Idealism and Romanticism has been and is so difficult because it is still unclear what the demonstration that there must be an 'unconditioned' aspect of subjectivity actually means. The need for responses to the world which are based on more than what the sciences can explain in terms of deterministic 
laws is still relatively uncontentious in many areas of philosophy, but how far does this take one in terms of metaphysical commitments, for example, to the idea that nature in itself is inherently subjective, and thus 'unconditioned' in some respect? In the face of the ecological crisis we are perhaps less likely to reject such ideas out of hand and are perhaps even able to understand the arguments of philosophers of this period better than they understood themselves. ${ }^{3}$ Their attention to art is, in this perspective, not just a concern with the icing on the cake of a post-theological world. It is rather a response to the feeling, already present in Kant's account of the genius, that 'external' nature is not just a causally determined object and is part of ourselves as subjects in ways we cannot explain, and perhaps could not ever fully explain.

\section{A 'new mythology'}

Both Idealism and Romanticism are aware, as was the younger Marx, that the revelation of the hollowness of theology does not lead to the disappearance of the needs which gave rise to it. The 'opium of the people' does not just numb the capacity for resistance by obscuring the real nature of a humanly created oppressive reality, it also kills the pain of meaninglessness by making negativity part of something which can transcend it. Replacing dogmatic theology is one of the major tasks of modern German philosophy from Idealism to Feuerbach, to Marx, Nietzsche and beyond. The concern, in both Idealism and Romanticism, with mythology should therefore not be lightly associated with later reactionary appropriations of mythology in terms of the need for a return to primordial origins with which we have supposedly lost contact in modernity. The essential attribute of mythology in this context is rather its use of a story about particular beings to tell a general story about the meaning and nature of reality.

The so-called 'Oldest System Programme of German Idealism' (SP) (reprinted in the Appendix), is a manifesto for a new philosophy and exemplifies the spirit of early Idealism, not least with regard to mythology. It was written down in the hand of Hegel (in June 1796?), has some of the characteristics of the thought of the young Hegel, but many people would consider that it was probably written by Schelling. ${ }^{4}$ (Some consider neither to have been the actual author.) The impetus of the text was suggested in Szondi's remark at the beginning of this chapter: it wants to re-unify the world that has been split up by Kant's critique of traditional metaphysics, at the same time as reinforcing Kant's insistence on our capacity for self-determination. Beginning with Fichte, German Idealism attempts, for reasons explained more fully in the next chapter, to give a more emphatic role to the free activity of consciousness than is evident in Kant's cautious formulations. The $S P$ is a manifesto and has no pretensions to coherent argumentation. Despite this it makes certain major issues very clear.

The basis of the $S P$ is a radical notion of freedom: 'The first idea [Idee] is 
naturally the notion [Vorstellung] of myself as an absolutely free being'. As was evident in Kant, once theological 'dogmatism' ceases to define our place in the world the creation of our relation to the world becomes the task of rational beings. Whereas Kant did not wish to make absolute claims for the ego, because this would require intellectual intuition to back up claims about the selfdetermining nature of the I, the $S P$, in the light of Fichte's Wissenschaftslehre (Doctrine of Science), has no doubts about the absolute freedom of the intelligible self. When the SP asks: 'How must a world be constituted for a moral being?' the question is, significantly, posed from the side of the subject that will alter the world, rather than from the side of a world into which the subject should fit. The text then jumps abruptly to the demand for a 'new physics', suggesting how far such thinking is from simply adopting Kant's clear boundaries between the realm of the understanding and reason. Such a demand becomes comprehensible in the light of Schelling's and Goethe's conviction that nature, even within the realm of natural science, should not be just regarded as an object to be brought under causal laws. The immediately following abrupt attack on the state as a 'machine' that cannot correspond to the 'idea' of mankind is inseparable in such thinking from worries of the kind we saw in Chapter 1 about modern science's turning nature into a machine.

In Kant's philosophy, the antidote to the mechanistic view of nature was the conception that natural organisms could be understood as functioning as if they followed an 'idea', an idea being what makes an object into more than the sum of its observable attributes. Kant linked the organism to the artwork produced by the genius, thus linking natural teleology, the growth of the organism into its particular form, and artistic production of a whole which is more than the sum of its parts. The idea of the organism is fundamental to the $S P$ and is derived from Schiller's response to Kant in his Letters on the Aesthetic Education of Man (1795). Manfred Frank defines organisms as 'structures whose parts take part in the purpose of the whole and in such a way that the purpose is not external to them, but, rather, their own purpose' (Frank 1982 p. 188). In order for the state to become an organism the individual organisms in it must be united to form a greater organism: for this they need a purpose. A purpose justifies a new state of reality not in terms of what is known of reality up to now but in terms what reality ought to become. As Frank puts it: 'Whilst only understanding is necessary to comprehend the mechanical linking of states of matter . . . in order to perceive purposes one needs reason ... the capacity to turn plans into deeds . . . a purpose is not something given [gegeben], it is a task [aufgegeben]' (p. 158). Reason is a potential which we have in us, hence, as we saw, the idea that it is 'infinite', because it is not defined by the way things already are.

The culmination of the conception of the organism, even for Kant, is the idea that if nature as a whole is thought of as an organism there must be a purpose in nature which can be linked to human purposes and activities. Access to such a purpose would enable one to legitimate a form of social organisation which could bring us into harmony with what we are as part of nature. This purpose, 
it should be remembered, need not be seen as a controlling divinity: Kant does talk about nature's purposes, but this can be construed in terms of the idea that spontaneous self-determination is an inherent part of nature. On the other hand, if there is thought to be no purposiveness in nature in this wider sense, the consequence, as we shall see later in the work of Schopenhauer and Nietzsche, is a view of reality as a disintegrated series of warring forces that have no essential direction. The choice between what now seems to us an indefensibly optimistic metaphysical conception of the totality and what is in fact an equally metaphysical negative image of that totality increasingly seems a bad one, but what these conceptions articulate will not go away as long as ecological questions about the relation of human activity to the rest of nature are asked.

The $S P$ next introduces the 'idea that unites all ideas, the idea of Beauty, taken in the higher Platonic sense'. This follows from the reasons for Kant's introduction of the notion of reflective judgement and his connection of natural teleology to works of art. The idea of beauty is supposed to overcome the gap between laws of nature constituted via the understanding and what reason is to do with this endless diversity of particular laws. It is at this point that the $S P$ maintains that the 'highest act of reason' is an 'aesthetic act'. This aesthetic act would enable practical reason to integrate the truths produced by the understanding into a purposive whole. The work of art is purposively produced, via free human initiative; at the same time, it is accessible to the understanding because it is an object of 'intuition': you can see it, hear it, and so on. As such, it partakes of the two realms which Kant's first two critiques had sundered, and which he tried to unite in the third Critique. Manfred Frank suggests the consequence of this:

Even when I do not produce an aesthetic product, but enjoy one, I still must use my freedom. For nothing sensuously visible and reconstructable in thought is sufficient to impress the character of the aesthetic on an object of nature [i.e. the understanding cannot produce aesthetic judgements]. I must, in order to become aware of the freedom represented in the object, use my own freedom. (p. 158)

The aesthetic product thus becomes a utopian symbol of the realisation of freedom: in it we can see or hear an image of what the world could be like if freedom were realised in it. We can see it in this way precisely because of that aspect of self-consciousness whose basis cannot be articulated in concepts, if concepts are taken in Kant's sense as rules for identifying objects.

In the $S P$ an understanding of Kant's postulated 'kingdom of ends', which philosophy can only characterise in the abstract terms of a world where rational beings are 'ends in themselves', becomes available to intuition in the work of art. Bernhard Lypp has termed this view 'aesthetic absolutism', the 'invocation of the unity of absolute experience which rests upon the materiality of the aesthetic sense' (Lypp 1972 p. 13). Because the aesthetic product still remains, qua created object, in the realm of intuition, it is able to point to why the world of the senses is not radically separate from the intelligible world. What makes the 
work a work of art which gives aesthetic pleasure is our free judgement, which is independent of any instrumental relationship to the object. Without the sensuous art-object, though, we would have no access to how our freedom relates to the appearing world. This conception might sound as though it just makes into a certainty what Kant had been careful to leave in the realm of the 'as if'. However, even in Kant's terms there is more than just a determination of the object by the subject in aesthetic judgement. As Scheible puts it: 'Only where the subject for its part can be affected by the object, in the aesthetic judgement, can the object be really "known" [erkannt in the sense of "recognised"], as only here does it cease to be simply "determined" [bestimmt]' (Scheible 1984 p. 124). The transcendental subject's connection of intuitions in judgements of the understanding gives rise to a nature whose coherence depends solely upon the subject's determination of what can be connected within it according to fixed rules. The aesthetic sense, though, also involves a non-determining relationship to the object: the object affects us in ways about which the connection of phenomena in terms of rules can tell us nothing. The object can only affect us in this way because of our freedom, but that freedom is not evoked by every object and it depends upon a much more extensive ability of thought to integrate particulars into significant wholes than that required to subsume particulars under rules (though, as we have seen, the separation between these two kinds of judgement cannot be absolute).

As I suggested in Chapter 1, Kant's distinction between the beautiful and the sublime creates the conceptual space for issues of aesthetics and politics from this time onwards. The $S P$ 's view of beauty is not just based on the - often highly questionable - political import of organicist ideas. Another political dimension, which plays a decisive role in later debates over aesthetics and politics, is already apparent in the SP's scepticism about abstraction, in the sense of the lack of connection of general rules to what those rules might mean to individual human subjects in the life-world. Philosophy without aesthetic sense, the $S P$ claims, is based on the understanding's quantitative, rule-bound determination of objects, which ignores both their sensuous particularity and the ways in which they may meaningfully cohere with each other. In a philosophy without aesthetic sense even the imperatives of practical philosophy, the basis of concrete ethical life, involve the danger of abstraction, because they may, in their theoretical form, be either incomprehensible or lacking in any motivating force for most people. The philosophical exploration of the relationship between the sensuous and the intelligible is, then, closely connected to major political issues in modernity. How abstract imperatives are to be made accessible and desirable in the public sphere remains an inescapable political issue. Art's attachment to sensuousness therefore points to its political potential, but at the same time it gives rise to important suspicions. Kant's introduction of the sublime and his approval of the ban on images in Jewish theology imply that the sensuous world is really there to be overcome, because it blocks participation in our higher purpose, which is independent of anything given in sensuous nature. Suspicion 
of the sensuous will, as we shall see, also be important in Hegel's Aesthetics, where art constitutes a lower form of truth because of its dependence upon particular sensuous manifestation. Significantly, this suspicion will become a major target in Feuerbach's and Marx's attacks on Hegel, and in the later Nietzsche's attacks on philosophy's desire to escape the sensuous.

Kant himself was in the position of Schoenberg's Moses, trying to persuade people believe in a God - reason - which they could not see, and often doing so in a language largely devoid of aesthetic appeal. It is clear, though, as anyone teaching philosophy knows, that key abstract ideas can often best be explained by trying to tell stories about them. Derrida's work can, for example, be read in this perspective as revealing how such stories may not even be separable from the ideas at all: the metaphors on which philosophy lives are not a dispensable extra. As Hamann's conception of language as inseparable sensuous sign and intelligible meaning already suggested, the very idea of a boundary between the sensuous and the intelligible can be questioned, and Derrida's concern with deconstructing such oppositions is in this sense part of the Romantic tradition. Analogous ideas to Derrida's are, of course, legion in post-Kantian philosophy: the deconstruction of the sensuous/intelligible divide is prefigured, as we shall see, in Schelling's notion of 'absolute indifference', in which there cannot be an absolute division between the sensuous and intelligible because they are inseparable aspects of the same infinite continuum.

For radical Enlightenment thinkers, like the early Schelling, this too is a political issue. The disintegration of the theological world view brings with it a loss of collectively accepted concrete stories, of the kind which used to be present in mythology, that revealed supersensuous truth via the sensuous world. Works of art, which articulate collective concerns and retain something of the status attached to cult objects, are accordingly regarded as offering the possibility of re-uniting a world which the abstractions that govern the modern world have begun to pull apart. The modern destruction of mythical forms of coherence need not, of course, be interpreted just in terms of loss. Habermas considers the differentiation of cognitive, ethical and aesthetic spheres in modernity, which excludes authority-based myth from knowledge that is open to public debate as to its validity, to be a key to the advances made possible in modernity. However, this separation is already perceived by Idealist and Romantic thinkers as also involving dangers, which a new mythology would try to overcome by a new synthesis of art and science. The Idealist and the Romantic perception is of the need to find novel ways of linking individual ways of making sense, which have an inherent basis in sensuous intuition, both to the results of the activity of the understanding and to the purpose of these results as a means of gaining control over nature.

The vital factor here is the imagination. Novalis suggests in the light of Fichte, who takes up and extends the grounding role of the imagination in Kant, that 'All inner capacities and forces and all outer capacities and forces must be deduced from the productive imagination' (Novalis 1968 p. 413). If science 
depends on the production of schematised images which are processed by the understanding, this production can be seen as more fundamental than the one particular kind of synthesis achieved by the understanding. Indeed the imagination can be understood as what makes being intelligible, instead of remaining opaquely enclosed within itself. ${ }^{5}$ The structure of seeing something as something which is made possible by what Kant explains in terms of schematism need not result in determinate cognition, as the ability to create metaphors new ways of 'seeing as' - suggests. In this respect what the imagination produces seems to span both art and science. Taken a step further, nature's own productivity might seem not be essentially different from our own production of forms of coherence in our coming to know about nature: the new science adumbrated in the $S P$ would in this view reflect the conviction that the genesis of the natural 'product' and the genesis of the knowledge of the product are ultimately of the same order.

Such ideas have too often been written off as pure speculation. Interestingly, though, the kind of speculation linking aesthetic and scientific praxis characteristic of the Romantics and of Schelling's Naturphilosophie does produce a lot more than merely speculative scientific results. Thinkers like Rorty have argued that radical new theories initially take the form of metaphors, in that they are not meaningful in terms of the existing forms of linguistic usage, and the metaphors only become literalised when they are generally accepted and move into common usage. The fact that the discovery of ultraviolet, theories of the ice age, and electromagnetism, for instance, are all worked out as part of Romantic science suggests the plausibility of such views. Looking at the genesis of new science often reveals that it is not merely the result of new rule-based judgements based on detailed inference. Instead, imaginative leaps which reconfigure the whole area in question are required if the previously accepted picture is to be replaced. Recent speculative science also seems to confirm this. Stephen Hawking, whose enormously successful A Brief History of Time seems at times to breathe the air of Idealist and Romantic science, has remarked upon the extent to which he initially thinks in images rather than in mathematical formulae. The perception of science which develops later in the nineteenth century in Germany and which still dominates much of the contemporary public image of scientific practice is generally suspicious of such ideas. Significantly, though, they have returned in the light of the new physics and of the contemporary changes in the perception of science effected by Kuhn, Foucault and others, most of whom are demonstrably dependent upon ideas deriving from the period at issue here.

Whatever one may think of the validity of Idealist and Romantic ideas for the philosophy of science, they do also suggest how the relationship between the theoretical and the sensuous is a still barely understood dimension of the politics of modernity. With the emancipation from tradition of the subject's capacity to describe the world, the awareness becomes explicit that objects can be articulated in an indefinite number of ways, whether this is, for example, in high 
art or in advertising. Objects consequently lose any sense of possessing binding truth for a community, but gain the potential endlessly to be re-described and re-articulated, though this in turn carries with it the threat of mere arbitrariness. The understanding, on the other hand, seeks to process objects in such a way that they are reduced to being candidates for truth only in the respect in which they can be subsumed under explanatory laws. As we have just seen, for Kant and his successors, the source of both these approaches to objects is the imagination. The problem of induction, to which Kant responded with his notion of reflective judgement, suggests how this issue is inevitably bound up with both the cognitive and the aesthetic. Even the understanding can produce an indefinite number of possible laws for any phenomenon, and there seems to be no essential criterion which would guarantee which is the correct law: establishing this seems to rely on judgements of coherence with other explanations which are analogous to aesthetic judgements. When played out in the social world what is involved in the issue of the imagination again takes on a more political dimension, of the kind indicated by the $S P$. Although natural science relies for its validity claims upon the exclusion of individual imaginative articulations of the object, it does increasingly have recourse to the aesthetic when it comes to the attempt to communicate scientific claims to the rest of society.

This tension between the cognitive and the aesthetic relation to the object plays a vital role in the culture of modern capitalism, which, as Marx's theory of the commodity claims, leads to objects becoming involved in processes of abstraction not unlike the constitution of an object of science by the understanding. The object as exchange value is abstracted from all its sensuous particularity in order to make it exchangeable for any other commodity. This leads to the need for ways of restoring the role of sensuous particularity if the commodity's abstract status is not to diminish its desirability. Advertising's continual raids on the sphere of art can therefore be understood as seeking to give back an individual sensuous appeal to the object of exchange value. The object qua exchange value needs the adjunct of the aesthetic image for it to function as a desirable use value. Furthermore, the consumer's 'need' for the object may itself have initially been stimulated by the aesthetic images attached to the object, which are used to add a gloss to its status as, say, just another cancer-causing cigarette. $^{6}$

Aestheticisation of commodities creates an increasingly difficult situation for serious artists who have often responded to it with a revolt against sensuous beauty. Their need is to escape complicity with the adding of aesthetic pleasure to exchange values and thus to sustain the notion of art as being independent of appropriative interest and as a continuing challenge to established ways of seeing. This is one root of the emergence of avant-garde art, which tries to escape existing forms of communication and often makes no attempt to be sensuously pleasing. In this way the limits of representation suggested by the notion of the sublime become a matter of cultural politics. The development of the avant-garde can, in this respect, be seen as connected to the failure of the 
sort of hopes suggested in the $S P$. The synthesis of sensuous image and abstraction seems only to take place in a collective manner in contemporary societies in the sphere of advertising and in the manifestations of administered mass culture. It does not take place in a new political public sphere in which the aesthetic is an integrated part of culture that includes all dimensions of human existence. That such syntheses take place in this way in mass culture is, though, not something to be judged in moralising terms. The needs which are being catered for are real, however illusory their fulfilment may be. Modern societies are evidently intolerable to their members without some sensuous way of relating to the technological and economic developments within those societies, however much these actually depend upon the elimination of sensuous particularity. The increasing incursion of the admen into the world of science, technology and economics is an expression of people's ineliminable need for a re-integration of dimensions of modern existence whose internal development increasingly separates them from other dimensions of that existence.

When Habermas maintains that philosophy today might 'at least help to set in motion again the frozen interplay between the cognitive-instrumental, the moral-practical and the aesthetic-expressive, which is like a mobile that has become stubbornly entangled' (Habermas 1983 p. 26) he in fact echoes ideas from the $S P$, a text of which he is otherwise generally critical. The $S P$, then, points to coming dangers which result from the way Kant's separation of understanding and reason is manifested in the historical world. It is in this perspective that one has to understand the call for a 'new mythology' that would link the abstract and theoretical notions of philosophy and science to sensuous experience, in the form of images and stories. The mythology demanded is, remember, a mythology of reason: the point is that it is up to us to make it, in the same way as Kantian reason is the task we have as autonomous beings. The $S P$ concludes with the demand for a 'polytheism of the imagination and of art', and a 'mythology of reason', which would synthesise the potential released by science, art and critical philosophy in the manner that myths integrated the contradictions between nature and society in traditional cultures. As the $S P$ puts it: 'Before we make the Ideas aesthetic, i.e. mythological, they are of no interest to the people and on the other hand before mythology is reasonable the philosopher must be ashamed of it.' Such a view is echoed in Gramsci's conception of hegemony: if intellectual developments are not just to reinforce existing power structures, ways must be found of communicating those developments to the people, in order that they can make them effective in political emancipation. The synthesis of aesthetics and reason in the name of the radical democratic politics demanded by the $S P$ is consistent with the Idealist philosophical desire to reveal the higher unity in the diversity of the sensuous world and thus to prevent a disintegration of the world into merely instrumentalised particulars. This again points to the extent to which the philosophy of the period is inseparable from political and cultural concerns. The failure of the vision of the $S P$ will suggest the political failure of this version of the Idealist project. It also 
points to the difficulties that will be faced by Marxist theory in coming to terms with the significance of art in a world where the collective theological or mythical basis of society has disintegrated.

\section{Early Romantic 'nem mythology'}

The division that can be made between Idealist and Romantic thinking depends upon the extent to which each thinks it possible to restore unity to what the modern world increasingly separates. In the main the Idealist response to the divisions in modernity is to seek new philosophical foundations on the basis of the Cartesian and Kantian conception of the founding role of self-consciousness. For Idealism, what philosophy can analyse in the activity of consciousness is a higher form of the intelligibility present in nature, so that the task of philosophy is to show how our thinking is the key to the inherent intelligibility of things. The essence of the Romantic response, on the other hand, is a realisation that, while it must play a vital role in a modern conception of philosophy, the activity of consciousness is never fully transparent to itself. It can therefore never be finally incorporated into a philosophical system, because what we can consciously know of ourselves does not exhaust what we are (see Bowie 1997, Frank 1997). ${ }^{7}$

The initial proximity of the Idealist and Romantic conceptions is apparent in the fact that Friedrich Schlegel's Discourse on Mythology (1800) seems to rely upon a similar relationship between art and mythology to that indicated in the $S P$ and the $S T I$. However, Schlegel begins to break with a central assumption of the $S P$. He thereby already suggests reasons for the emergence of the notion of aesthetic autonomy, the modern idea that art is subject only to its own necessities. Aesthetic autonomy will become particularly significant in the light of the failure to synthesise the sensuous and the theoretical in an Idealist 'new mythology'. Karl Heinz Bohrer has claimed that: 'Schlegel's Discourse on Mythology is precisely "new" in that the "new mythology" which it announces, as opposed to the demand of the System Programme and to the aesthetics of the young Schelling, is expressly not "in the service of the Ideas", i.e. not a "mythology of reason"' (Bohrer 1983 pp. 56-7). The reason for this claim is that Schlegel's argument moves away from the emphasis seen in the $S P$ on revolutionary demands for new forms of communication in the political public sphere. The sense that human creativity is linked to a wider purpose in nature here already begins to give way to an ontology of spontaneous, non-teleological creativity of the kind later to be seen in Nietzsche's The Birth of Tragedy. Schlegel therefore loosens the links between aesthetics and ethical goals present in Idealism. Bohrer suggests - although in doing so he exaggerates the extent to which this is important in the Discourse and largely ignores the fact that in many respects the early Schlegel remains committed to the task of reason - that Schlegel initiates 'aesthetic reduction': 'the reduction of the time of the philosophy of history to an ecstatic moment' (p. 59). 
Such a reduction is apparent in Schlegel's notion of Witz ('wit'), the capacity to create random correspondences which suggest a unity of totally diverse phenomena, and thus of the whole world, in the manner of a myth. However, the crucial difference of wit from mythology is that it is characterised by randomness, suddenness and transience, rather than possessing an enduring meaninggiving function. Art thus begins to involve a temporality which no longer points beyond itself, exists only in the present of the engagement with the work, and is irreducible to anything else. The temporality in question here will, of course, be a central issue in modernist art: Proust's moment privilégié and Joyce's epiphany, for example, echo what Schlegel intends. The other aspect of art highlighted by Schlegel is allegory, which he understands as being a result of the impossibility of presenting a positive account of the absolute. Allegory points beyond itself and it is therefore not, as a symbol is, a sensuous embodiment of what it means. In this respect allegory is analogous to Kant's sublime. For Schlegel, then, one is left with the alternative between the evanescent transcending of the sensuous in wit and a failure to represent a transcendent unity in allegory, rather than with a way of seeing art as the sensuous manifestation of the infinite. The aptness of these ideas is already evident in the extent to which they become preoccupations of so much modernist art from this time onwards.

In the Athenäum Fragments Schlegel claims: 'A philosophy of art in general [der Poesie überhaupt $]$ would begin with the independence of the beautiful, with the proposition that it is separate from the true and the moral and should be separate from it and have the same rights as it' (Schlegel 19882 p. 129 Fragment 252). The culmination of this idea will be Nietzsche's contention in The Birth of Tragedy that the only justification of existence itself is as an 'aesthetic phenomenon', which is contemplated immediately for its own sake because it lacks any teleological justification. Schlegel, though, does still retain the idea that art can point beyond itself towards an unrepresentable absolute, which would, of course, connect it again to the cognitive and the ethical. This suggests an important division in modern thought, between early Romanticism and the more questionable tendencies which emerge from it, which have no concern with the ethical implications of the aesthetic. The problem of the modern artist is, Schlegel claims, that he must 'work out from the inside' and create 'every work like a new creation from nothing' ( 2 p. 201). Modern art lacks a 'centre', of the kind that mythology represented for ancient cultures, from which to derive collectively binding images and symbols. Schlegel insists that the new mythology cannot use 'the nearest and most lively aspects of the sensuous world' in the manner that Greek mythology did, and 'must on the contrary be formed out of the deepest depths of spirit [Geist] ; it must be the most artificial of all works of art, for it is supposed to grasp all other arts within it, a new bed and container for the ancient eternal original source of poetry' $(2 \mathrm{p}$. 201). The new mythology would link all forms of articulation, from the arts to the sciences, hence the need for it to be artificial, a synthesis in a new kind of culture of what modernity separates into differing spheres. 
The crucial difference of Schlegel's position here from that of the $S P$ resides in the fact that he sees Poesie as originating in the negation of the 'progress and laws of rationally thinking reason'. We should instead be plunged into 'the beautiful confusion of fantasy, into the original chaos of human nature, for which I know of no better symbol until now than the colourful swarm of the ancient Gods' (2 p. 204). Schlegel wishes to explore the creative potential in every particular sensuous object - if laws of reason are suspended anything can be the occasion of the operation of fantasy - which leads to an endless proliferation of possible articulations. This was, of course, the sort of thing which Kant warned against in his reflections on the sublime. The difference between Kant's concern that one should not to spend one's time seeking something which is more than sensuous within the sensuous, and Schlegel's Romantic position, is a precursor of some of the main divisions in the aesthetics of modernism. Modernist aesthetics is located between the tendency to abolish art altogether by revealing its ineradicable attachment to the sensuous, and the tendency to elevate art to a status possessed by no other aspect of the modern world on the basis of the idea that it is the only thing which can still take us beyond the sensuous, albeit in an essentially arbitrary manner. Schlegel's proximity to Hamann's Aesthetica in nuce is also evident here. Both regard mythology and art as deriving from the same source: an endless process of articulation at all levels of nature and of human activity: 'Mythology is . . . a work of art of nature . . . everything is relation and transformation, formed and reformed' (2 p. 204).

The further question in this context is how the subject relates to this process of 'relation and transformation', which functions in a manner which is not under the subject's control. Lévi-Strauss's structuralist account of mythology, whose analogies to aspects of Romantic thinking are apparent in its connecting of music to mythology and mythology to language, is seen by Paul Ricoeur as suggesting that mythology is 'a categorising system unconnected with a thinking subject ... homologous with nature; it may perhaps be nature' (Lévi-Strauss 1975 p. 11). Lévi-Strauss was influenced by C.G. Jung, who himself relied on elements of Schelling's early Naturphilosophie and later Philosophy of Mythology of the 1840s. Schelling suggests in 1841 that in mythology: 'the ideas (Vorstellungen) are products of a necessary process, or of natural consciousness which is left to its own devices, on which there is no influence of any free cause' (Schelling 1977 p. 250). Schlegel is similarly not concerned with the reflecting, intending subject at this point: the vital aspect is the surrender to the other, the loss of identity. This can be construed as a return to a more 'natural' way of being, as it often is in later Romantic theories and in subsequent reactionary politics, but it can also be interpreted in a perhaps less questionable manner. Unsurprisingly, given its links to Romanticism via Nietzsche, certain tendencies in post-structuralism parallel notions of a subjectless generation of difference of the kind suggested by Schlegel. The root of such conceptions of endless formation and reformation is the renewed interest in the myth of Dionysus that develops in the second half of the eighteenth century. Importantly for my 
overall argument, this interest becomes linked to the increased significance attached to music at this time.

Hamann had already prophetically linked Dionysus to art in Aesthetica in nuce (1762): 'Do not dare enter the metaphysics of the arts without being versed in the orgies and Eleusinian mysteries. But the senses are Ceres, and Bacchus the passions; - old foster parents of beautiful nature' (Hamann 1967 p. 111). In the essay On the Study of Greek Literature (1797), Schlegel says of Sophocles that he amalgamates 'the divine intoxication of Dionysus, and the deep sensitivity of Athene, and the quiet collectedness of Apollo' (Schlegel 19881 p. 107). Dionysus is seen here as the principle of disintegration which needs to be balanced by forces which give form to chaos. In Der kommende Gott (The Coming God) Manfred Frank explains how the figure of Dionysus plays an important role in both Idealist and Romantic thinking, making clear that the decisive aspect in the new understanding of this myth is the way in which it involves an inherent identity of opposites:

Dionysus is the God who does not have a high opinion of the principle of individuation, who drags everything into the frenzy, makes 'women into hyenas', tears down the barriers between the sexes, and in general manipulates the separate realms of being as he wishes, by on the one hand pulling them down into the whirlpool of undifferentiated identity, on the other, as the liberating God dedicated to progress and evolution, separating the realms of being anew and - in the literal sense of the word - differentiating them. Thus he participates both in the principle of unity and of separation. (Frank 1982 p. 20)

The vital point is, then, that creativity is inseparable from destruction, and this apparent paradox is at the root of the philosophy of this period.

The myth of Dionysus involves a version of the identity of identity and difference', which is central to the thought of the early Schelling, and to Hegel. The fascination of Dionysus has two related sources. The story of the god that is destroyed and reformed can be linked to the story of Christ, as it frequently was from the eighteenth century onwards, and it clearly also played a role in the initial formation of Christian mythology. At the same time a key problem in Idealist and Romantic thinking which they inherited from Greek philosophy how can the universe be shown to be both one and differentiated within itself? - appears in the sensuous form of the story of Dionysus. This link of unity and division is itself one way of interpreting the passion of the son of God in Christian mythology. ${ }^{8}$ Dionysus, then, becomes the ground of the intelligible world, which produces endless sensuous forms out of itself. For both Schopenhauer and the early Nietzsche this ground will be most readily accessible in music. ${ }^{9}$ The initial reasons for this conception are best outlined here: the topic will frequently recur later.

The link of music to Dionysus can be better understood if we consider Schlegel's view of 'Romantic art' in the famous fragment 116 of the Athenäum. Romantic art is 'still in a process of becoming; yes, that is its real essence, that it 
can eternally only become, can never be completed. It cannot be exhausted by any theory' and multiplies itself 'as if in an endless row of mirrors' (Schlegel 19882 pp. 114-15). Romantic art is thus analogous to Dionysus, the god who combines creation with destruction: each relation of the work to something else (in 'reflection', which can include theoretical explanation of the work) is negated in the next relation, but the overall process of relation between work and world cannot come to an end because there is always more to be said. Whereas the Idealist new mythology would constitute a binding together in collective forms of the products of modernity, this view involves the unleashing of a world of decentred diversity. The process of 'infinite reflection' in Romantic art is initially associated with music because of music's dependence upon the passing of time for the different moments of a piece of music to become linked in a significant manner. The condition of the identity even of the whole of a piece is the difference of its moments in time, a thought which is consistent with the Idealist conception of unity in diversity. However, what the musical whole signifies cannot be articulated in a definitive way: music is non-representational and seems, like Schlegel's allegory, to point beyond itself without our being able to say definitively what it is pointing to. It is this fact which makes music the form of art most likely to be associated with the failure to represent the absolute in a positive manner.

The relation of the idea of the 'new mythology' to music reveals a fundamental tension in modern art. Music inherently has the potential to sustain aesthetic autonomy via its non-representational character, and this is a major reason why it comes to be seen as a counter to the reduction of more and more of the world to scientific explanation. At the same time, however, music also becomes a major political issue, despite its distance from representation. Wagner will, for example, attempt to revive a nationalist mythology by creating music which moves beyond the existing formal norms and establishes new ways of integrating musical material. Wagner's project combines the political impetus of the $S P$, albeit in a distorted form, with the Romantic view of the liberation of the aesthetic from pre-given rules. The power of the resulting works, and their highly questionable subsequent reception and use as ideology, particularly by the Nazis, make it evident that aesthetic issues go to the very heart of modern politics. Analysing what is at stake in such aesthetic questions for the history of modern self-consciousness will be one of the major tasks of the chapters which follow.

The idea of the 'new mythology' has deeply worrying resonances in the light of the events of twentieth-century history: the most spectacular - albeit temporary - political success of a 'new mythology' was, of course, that of the Nazis. It is therefore no coincidence that Walter Benjamin, no stranger to the thinking of this period, attacked the Nazi use of mythology as the 'aestheticisation of politics'. It has also been argued that the failure of the Left to establish at least some aspects of a 'rational mythology' was a major factor in its inability to gain the kind of support required to defeat Hitler. Ernst Bloch and Benjamin were well aware of the irrationality of the mobilisation of energy via aesthetic means by 
the Nazis. Bloch, in particular, was also aware, however, that the ability to make 'ideas' - purposes which do not depend on the way the world already is - available in a 'sensuous' manner is vital to any political project, as is the ability to find ways to articulate what was previously articulated in the religious feeling of belonging to a greater whole.

The consequences for art of trying to come to terms with these conflicting demands can, of course, be catastrophic. Much of the tension in debates over aesthetics and politics in the twentieth can be related to the issues glimpsed in the $S P$ and the Discourse. Neither the demand to make ideas aesthetic, as a means of making them more accessible to people's experience and wishes, nor the simultaneous demand to sustain the claims of reason, is ever fulfilled in a manner that is adequate to the kind of technical and social changes that take place in advanced capitalist societies. The failure to fulfil these demands is one source of the world of projection which we now inhabit, where the marketing of images increasingly takes over from the attempt to deal with real socio-economic and cultural problems. The driving of art into the radical autonomy of the avant-garde is a reflex of this situation, but the difficulty such art faces is that refusal to share the communicative means of a society can only ever be temporary. Modernist art of the twentieth century is always eventually incorporated into the commodity-sphere: even Schoenberg can be made use of in an aesthetically insignificant manner for film music. In order to understand the further implications of the questions outlined here one must retrace the philosophical story of their emergence. Much of what is debated in this area today can be better understood by considering the conceptual resources generated in the reactions to Kantian philosophy in Idealism and Romanticism.

\section{Notes}

1 For a much more detailed and differentiated view see particularly Frank 1997.

2 In this sense the crucial implications of early Romanticism are in fact much closer to contemporary pragmatism than to metaphysical realism.

3 This idea is suggested by Kant in relation to Plato in the $C P R$, and is developed by Schleiermacher: see below Chapter 6 .

4 See, for example, Xaver Tilliette: 'Schelling als Verfasser des Systemprogramms?' in eds. Frank and Kurz 1975 pp. 193-211. Recent debate suggests both Hegel and Hölderlin as the author (see, e.g. Förster 1995, eds, Baur and Dahlstrom 1999).

5 Heidegger makes Kant's schematism chapter central to his reformulation of the question of being in his work in the 1920s.

6 Clearly the other vital aspect here is the employment of sexual images, but these are themselves aestheticised.

7 This is why so many accounts of Romanticism, which, like that of Isaiah Berlin, assimilate it to Idealism via the influence of Fichte are mistaken. I shall deal with this issue in more detail in the next chapter.

8 This is one of the reasons why the figure of Dionysus is so important for Hölderlin. The idea of unity in division also echoes the concept of the Trinity.

9 As we shall see in Chapter 8, it is Schelling who first makes this link. 